\title{
Dynamic analysis of an impact load applied to the composite wall structure
}

\author{
Maciej Major ${ }^{1}$, Krzysztof Kuliński ${ }^{2}$ and Izabela Major $^{3^{*}}$ \\ ${ }^{1}$ Technical Sciences, Department of Steel Constructions and Building Materials, Faculty of Civil \\ Engineering, Częstochowa University of Technology, 42-200 Częstochowa, Poland \\ ${ }^{2}$ Technical Sciences, Department of Concrete Constructions and Geotechnics, Faculty of Civil \\ Engineering, Częstochowa University of Technology, 42-200 Częstochowa, Poland \\ ${ }^{3}$ Technical Sciences, Department of Technical Mechanics and Engineering Graphics, Faculty of Civil \\ Engineering, Częstochowa University of Technology, 42-200 Częstochowa, Poland
}

\begin{abstract}
In presented paper the composite wall structure made of concrete and Zahorski/Mooney Rivlin rubber cross pads subjected to impact loads was investigated. Mentioned rubber cross pads were assumed to be inserted or injected in specially formed holes during the production process. Moreover, two different impact loads were taken into further considerations - pressure and concentrated force. Such impact loads due to the small time step size allowed observation of mechanical wave propagation in analyzed structure in the form of stress plots. On the basis of composite wall comparison with the solid concrete wall it could be stated that the mechanical wave propagation was significantly damped via inserted/injected rubber cross pads. Discussed problem was solved with the use of finite element method using ADINA program.
\end{abstract}

\section{Introduction}

Composites due to their more preferable mechanical properties in comparison with individual materials are the subject of interest by many researchers. The most popular composite utilized in civil engineering are concrete with steel and steel with rubber. Utilization of composites allows mainly reduce the total mass of construction in comparison with the structure where individual material is used, reduce the influence of unfavourable effects, exploitation costs, improve forces redistribution etc.

Mechanical wave propagation is one of mentioned negative effects, which should be strongly avoided in newly designed structures. Such mechanical wave propagation in any considered material may be a result of earth movement vibrations, acoustic waves propagation, explosion blasts etc. The problem of wave propagation was discussed by Major and Major [1], where authors presented the possibility of numerical solutions with the use of finite element method in the ADINA program. However initial concrete or ceramic blocks acoustic/vibrations absorption property may be improved with the additional material utilization as a cover of host wall - such as polystyrene foam or mineral wool, the width dimension of such wall would also be increased. Such increase in structure

* Corresponding author: imajor@bud.pcz.czest.pl 
dimensions is often undesirable from the designing point of view, especially in small structures with small interior area.

In this paper composite blocks made of concrete and rubber were proposed due to their significantly improved mechanical wave propagation damping properties in comparison with an individual solid concrete block. It is also worth to notice that discussed composite block allow transferring of significant compressive forces - load bearing capacity of such block in comparison with solid concrete block was only slightly reduced via specially prepared holes. It was assumed that the concrete block in the production process was embedded into special form and after its removal, rubber cross pads could be inserted or injected in mentioned holes. Moreover, three plane symmetry was assumed in order to eliminate possible assemblage mistakes. Two different material models representing rubber cross pads were adopted i.e. Mooney-Rivlin [2, 3] and Zahorski [4, 5], respectively. A similar analysis using the same materials was performed in the paper [6]. Additionally, two different impact loads were investigated - i.e. pressure and concentrated force. In order to determine the mechanical wave propagations resulting from applied loads, finite element method approach with the use of ADINA program was performed. Mechanical wave propagation phenomena were also the subject of interest of Coulson and Jeffrey [7], Kosiński [8] and Wesołowski [9]. Recently numerical approach is treated as an introduction to the expensive experimental tests or validation tool of already produced/constructed objects and structures (see [10]). As an example Cajka and Krejsa [11] validated the action of static and dynamic forces in repaired lightweight steel roof structure.

\section{Methods}

In order to perform numerical analysis of mechanical wave propagation, section of a wall made of composite blocks was adopted. Mentioned wall had following dimensions assumed - length equal $0.96 \mathrm{~m}$, height $0.68 \mathrm{~m}$ and thickness of $0.25 \mathrm{~m}$, respectively (see Fig. 1a). Each composite block had $0.47 \mathrm{~m}$ length, $0.25 \mathrm{~m}$ width and $0.22 \mathrm{~m}$ height. Inner mortars were assumed to be $1 \mathrm{~cm}$ thick. In Fig. 1a whole wall was presented with the effective stress measurement points $1-4$. It should be noted that points $1-4$ on the rear wall side were introduced with the suffix letter " $R$ " and were the reflection of points 1-4 from the presented frontal surface of the wall. Vertical and horizontal mortars with strength of 4 MPa were considered as $10 \mathrm{~mm}$ thick. Dimensions of all rubber cross pads were presented in Fig. $1 b$.

a)

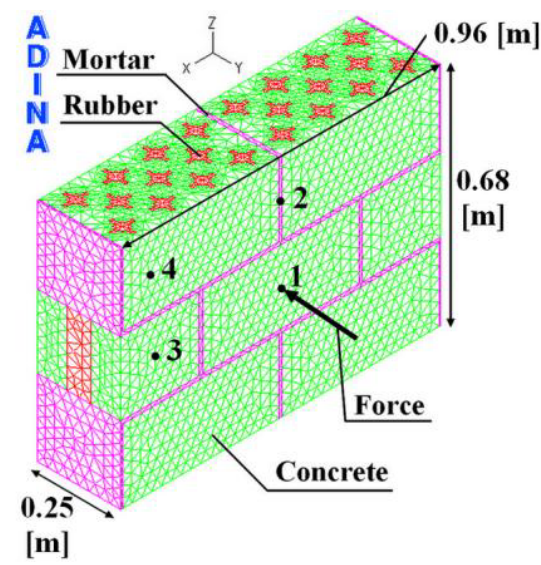

b)

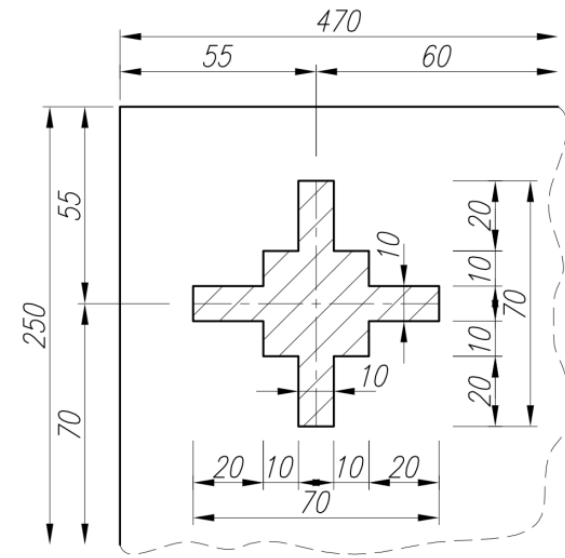

Fig. 1. (a) Wall numerical model made of composite blocks with concentrated force and measurement points $1-4$, (b) rubber cross pads placement with respect to the left top corner of concrete block. 
Dynamic pressure load with the value of $10000 \mathrm{~Pa}$ was applied on the whole frontal surface of the wall, whereas concentrated force with value of $5000 \mathrm{~N}$ was placed in the middle of front wall surface (see Fig. 1a). Both forces reached their maximum value at $t=1 \cdot 10^{-5} \mathrm{~s}$ and after that time, force was removed - their value was equal 0 . It should be noted that applied load values were treated only as a reference for comparative analysis between composite and solid concrete blocks. Three different time step values of obtained effective stress were taken into further considerations of obtained effective stress $t=1 \cdot 10^{-5} \mathrm{~s}, 5 \cdot 10^{-5} \mathrm{~s}$ and $9 \cdot 10^{-5}$ $\mathrm{s}$, respectively.

In presented model on exterior "YZ" and top "XY" plane surfaces of the wall X and Y axis displacements were fixed, whereas on the bottom exterior "XY" plane surface of the wall $\mathrm{X}, \mathrm{Y}$ and $\mathrm{Z}$-axis displacements were fixed.

Discretization of considered wall model was performed with the use of 4-node 3D-solid finite elements (tetrahedrons), where size of each element in composite/concrete block was assumed to be $\sim 0.02 \mathrm{~m}$. Discretization of rubber and mortars was performed automatically with respect to the previously defined nodes in the composite/concrete blocks. Numerical model comprised of 26722 nodes, 89993 finite elements describing concrete block, 38578 elements describing rubber cross pads and 20163 elements describing mortars, respectively. In case of solid concrete blocks exactly the same mesh was used, whereas rubber elements were replaced with concrete finite elements. According to that 26722 nodes, 128571 finite elements describing concrete blocks and 20163 elements describing mortars were obtained.

Concrete blocks were made of $\mathrm{C} 20 / 25$ class concrete described via ADINA "Concrete" material module, mortars with strength of $4 \mathrm{MPa}$ were described via ADINA "DF-Concrete", whereas rubber was represented via ADINA "Mooney-Rivlin" material module. In order to represent Zahorski material model description, the original ADINA "Mooney-Rivlin" material library was modified.

\section{Numerical results}

According to the fact that mechanical wave propagation transferred energy through analyzed model, effective stress redistribution was investigated. Obtained effective stress values in considered measurement points for both, wall made of composite blocks and wall made of solid concrete blocks were presented in Table 1. It should be noted that points with " $R$ " suffix were the reflection of located on the front wall surface points 1-4 onto the rear side of the wall.

On the basis of Table 1 and performed numerical analysis one can state that for the Mooney-Rivlin and Zahorski material model obtained results were exactly the same. Differences between that two mentioned materials can be observed mainly at large deformations. According to the Fig. 2 it is clearly visible that the mechanical wave energy at $t=5 \cdot 10^{-5} \mathrm{~s}$ was significantly absorbed via rubber pads and on the rear side of the composite blocks wall obtained effective stress was 37-65\% lower for the pressure load and 55 to $97 \%$ lower for concentrated force compared to the wall made of solid concrete blocks. In case of concentrated force, it is worth to notice that the longer distance from the applied dynamic force to the measurement point and the more rubber cross pads were on the way of disturbance propagation the higher percentage damping was obtained (compare point $3 \mathrm{R}$ and $4 \mathrm{R}$ with $1 \mathrm{R}$ and $2 \mathrm{R}$ in Fig. 2). However, at the $t=5 \cdot 10^{-5} \mathrm{~s}$ obtained effective stress values were lower in composites on the rear side of the wall compared to the solid concrete blocks, therefore at $t=9 \cdot 10^{-5} \mathrm{~s}$ for example in point $2 \mathrm{R}$ or 4 for pressure load obtained stress was higher. Mentioned situation was connected with the mechanical wave refraction and reflection on the rubber material surfaces. According to that transferred energy overlapped providing greater values of discussed stress. 
Table 1. Effective stress comparison in the given measurement points for composite wall and wall made of solid concrete blocks for two different loads at three different time steps.

\begin{tabular}{|c|c|c|c|c|c|c|c|}
\hline \multirow{3}{*}{ 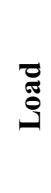 } & \multirow{3}{*}{$\overrightarrow{\underline{\theta}}$} & \multicolumn{6}{|c|}{ Effective stress [Pa] } \\
\hline & & \multicolumn{3}{|c|}{$\begin{array}{c}\text { Composite wall } \\
\text { (Mooney-Rivlin / Zahorski) } \\
\end{array}$} & \multicolumn{3}{|c|}{ Solid concrete blocks } \\
\hline & & $t=1 \cdot 10^{-5} \mathrm{~s}$ & $t=5 \cdot 10^{-5} \mathrm{~s}$ & $t=9 \cdot 10^{-5} \mathrm{~s}$ & $t=1 \cdot 10^{-5} \mathrm{~s}$ & $t=5 \cdot 10^{-5} \mathrm{~s}$ & $t=9 \cdot 10^{-5} \mathrm{~s}$ \\
\hline \multirow{8}{*}{ 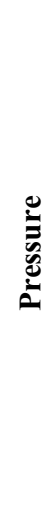 } & 1 & $5.34 \mathrm{E}+03$ & $1.20 \mathrm{E}+03$ & $1.30 \mathrm{E}+03$ & $5.29 \mathrm{E}+03$ & $8.93 \mathrm{E}+02$ & $9.39 \mathrm{E}+02$ \\
\hline & $1 R$ & 4.41E-02 & $3.04 \mathrm{E}+02$ & $1.70 \mathrm{E}+03$ & $2.12 \mathrm{E}-01$ & $4.81 \mathrm{E}+02$ & $2.32 \mathrm{E}+03$ \\
\hline & 2 & $1.39 \mathrm{E}+03$ & $3.08 \mathrm{E}+03$ & $1.50 \mathrm{E}+03$ & $1.36 \mathrm{E}+03$ & $2.66 \mathrm{E}+03$ & $1.78 \mathrm{E}+03$ \\
\hline & $2 \mathbf{R}$ & $7.16 \mathrm{E}-02$ & $4.11 \mathrm{E}+02$ & $9.15 \mathrm{E}+02$ & $9.69 \mathrm{E}-02$ & $7.06 \mathrm{E}+02$ & $3.97 \mathrm{E}+02$ \\
\hline & 3 & $5.72 \mathrm{E}+03$ & $2.73 \mathrm{E}+03$ & $1.52 \mathrm{E}+03$ & $5.69 \mathrm{E}+03$ & $2.60 \mathrm{E}+03$ & $1.19 \mathrm{E}+03$ \\
\hline & $3 \mathbf{R}$ & $2.35 \mathrm{E}-02$ & $1.57 \mathrm{E}+02$ & $1.88 \mathrm{E}+03$ & $1.53 \mathrm{E}-01$ & $4.50 \mathrm{E}+02$ & $2.12 \mathrm{E}+03$ \\
\hline & 4 & $5.69 \mathrm{E}+03$ & $4.85 \mathrm{E}+03$ & $3.84 \mathrm{E}+03$ & $5.75 \mathrm{E}+03$ & $3.43 \mathrm{E}+03$ & $1.72 \mathrm{E}+03$ \\
\hline & $4 R$ & 2.32E-02 & $1.72 \mathrm{E}+02$ & $2.45 \mathrm{E}+03$ & $1.30 \mathrm{E}-01$ & $4.20 \mathrm{E}+02$ & $2.63 \mathrm{E}+03$ \\
\hline \multirow{8}{*}{ 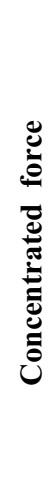 } & 1 & $2.12 \mathrm{E}+06$ & $5.02 \mathrm{E}+05$ & $3.25 \mathrm{E}+05$ & $2.12 \mathrm{E}+06$ & $4.97 \mathrm{E}+05$ & $3.08 \mathrm{E}+05$ \\
\hline & $1 R$ & $7.66 \mathrm{E}-01$ & $4.64 \mathrm{E}+03$ & $3.61 \mathrm{E}+03$ & $4.10 \mathrm{E}+00$ & $1.38 \mathrm{E}+04$ & $1.35 \mathrm{E}+04$ \\
\hline & 2 & $1.57 \mathrm{E}+00$ & $4.80 \mathrm{E}+03$ & $4.55 \mathrm{E}+04$ & $1.40 \mathrm{E}+00$ & $3.71 \mathrm{E}+03$ & $3.25 \mathrm{E}+04$ \\
\hline & $2 \mathbf{R}$ & $3.67 \mathrm{E}-03$ & $1.40 \mathrm{E}+02$ & $9.22 \mathrm{E}+03$ & $1.21 \mathrm{E}-02$ & $3.12 \mathrm{E}+02$ & $1.27 \mathrm{E}+04$ \\
\hline & 3 & $1.15 \mathrm{E}-03$ & $2.12 \mathrm{E}+01$ & $1.57 \mathrm{E}+03$ & $0.00 \mathrm{E}+00$ & $3.08 \mathrm{E}+01$ & $5.02 \mathrm{E}+02$ \\
\hline & $3 \mathbf{R}$ & $0.00 \mathrm{E}+00$ & $1.94 \mathrm{E}-01$ & $3.24 \mathrm{E}+02$ & $0.00 \mathrm{E}+00$ & $7.14 \mathrm{E}+00$ & $2.28 \mathrm{E}+03$ \\
\hline & 4 & $0.00 \mathrm{E}+00$ & $4.01 \mathrm{E}-01$ & $1.57 \mathrm{E}+02$ & $0.00 \mathrm{E}+00$ & $4.73 \mathrm{E}+00$ & $6.11 \mathrm{E}+02$ \\
\hline & $4 R$ & $0.00 \mathrm{E}+00$ & $3.94 \mathrm{E}-02$ & $9.50 \mathrm{E}+01$ & $0.00 \mathrm{E}+00$ & $1.35 \mathrm{E}+00$ & $7.33 \mathrm{E}+02$ \\
\hline
\end{tabular}

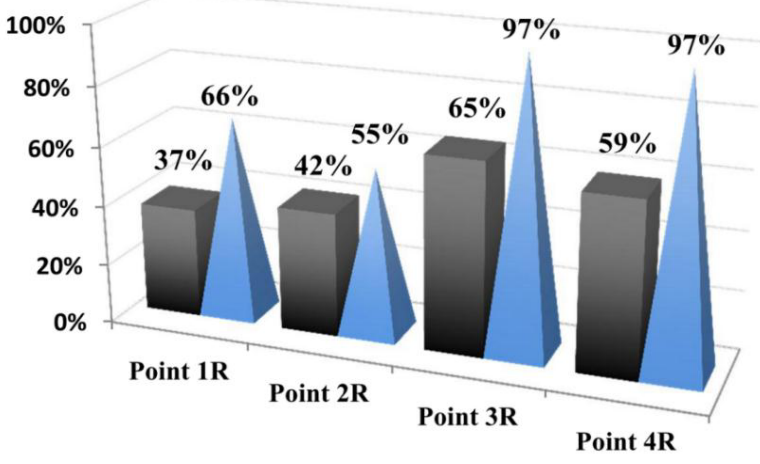

- Pressure $\quad$ Concentrated force

Fig. 2. Percentage damping of mechanical wave propagation for different measurement points and two types of load in composite wall related to the solid sandstone blocks wall at $t=5 \cdot 10^{-5} \mathrm{~s}$. 
Moreover, value of effective stress in the composite block at the start of the analysis $t=1 \cdot 10^{-5} \mathrm{~s}$ was slightly higher than in solid concrete blocks, which was connected with smaller overall volume of the concrete material - at first internal forces were distributed through material with higher rigidity, which in that case was concrete. Clearly visible mechanical wave propagation in the form of stress redistribution plots in the horizontal "XY" plane cross section passing through points 1 and 3 (see Fig. 1a) for the pressure impact load at $t=5 \cdot 10^{-5} \mathrm{~s}$ was presented in Fig. 3 while for the concentrated force at $t=7 \cdot 10^{-5} \mathrm{~s}$ was presented in Fig. 4 .

a)

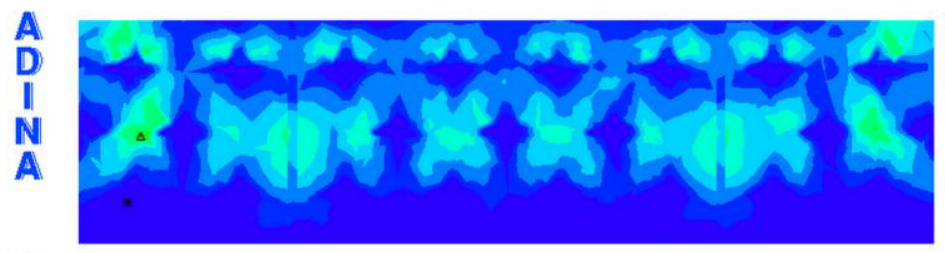

b)
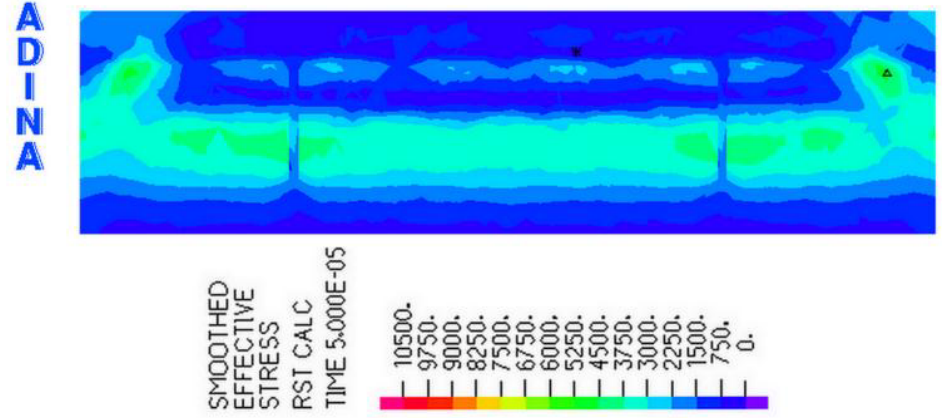

Fig. 3. Stress $[\mathrm{Pa}]$ redistribution plots from the pressure impact load at $t=5 \cdot 10^{-5} \mathrm{~s}$ in the wall made of (a) concrete-rubber composite blocks, (b) solid concrete blocks.

a)

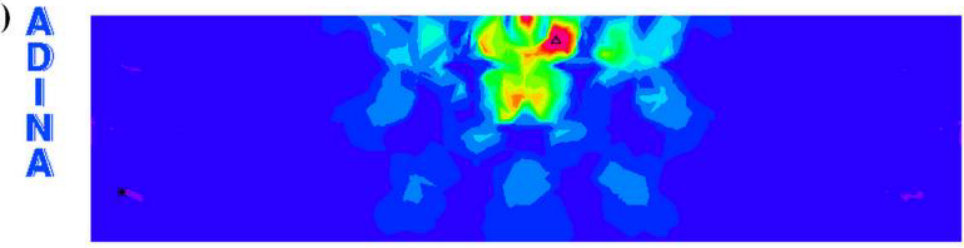

b)
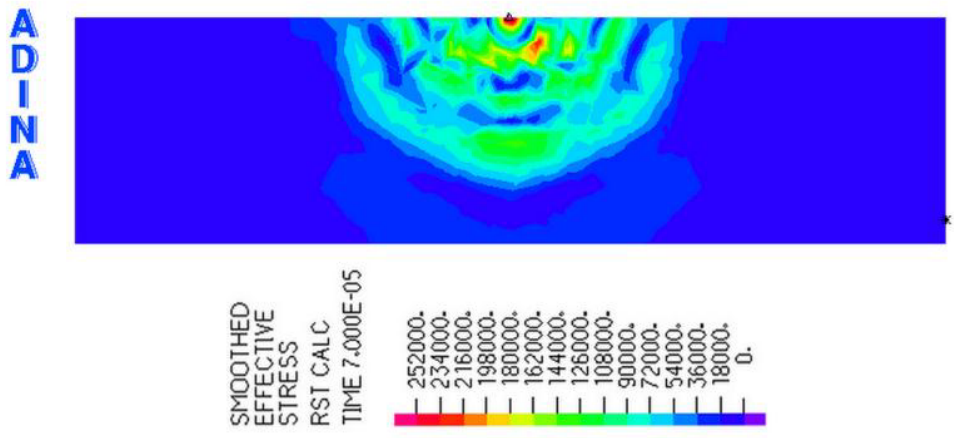

Fig. 4. Stress $[\mathrm{Pa}]$ redistribution plots from the concentrated force impact load at $t=7 \cdot 10^{-5} \mathrm{~s}$ in the wall made of (a) concrete-rubber composite blocks, (b) solid concrete blocks. 


\section{Conclusions}

In this paper mechanical wave propagation in two different types of wall was discussed. The reference numerical model was assumed as wall made of solid concrete blocks, whereas proposed new solution for the comprised of wall made of concrete blocks with specially formed holes in the production process, where rubber material could be inserted or injected. According to the performed numerical analysis it was shown that the mechanical wave propagation in wall made of composites could be significantly damped. Propagating wave on the rear side of the composite wall at $t=5 \cdot 10^{-5} \mathrm{~s}$, which was the time of wave passing through the block material from its front to rear surface was reduced in the range of $37-97 \%$ in comparison with the wall made of solid concrete blocks. Such high values of mechanical wave damping could be obtained due to the rubber mechanical energy absorption property i.e. rubber material elastic deformations. From the engineering and designing point of view presented composite could be easily utilized in civil engineering especially in areas exposed to small earth shakes, machines vibrations or to reduce acoustic waves. It should also be noted that due to the small area of the rubber cross pads the overall compressive forces bearing capacity was only slightly reduced in comparison with solid concrete block. Moreover, due to the three planes of symmetry the risk of incorrect block placement in the wall was utterly compromised. However, presented composite gave satisfactory results of mechanical wave damping via the numerical analysis, experimental tests should also be provided in order to estimate the actual load bearing capacity and other material properties unspecified in this paper.

\section{References}

1. I. Major, M. Major, Advanced Materials Research, 1020, 171-176 (2014)

2. M. Mooney, Journal of Applied Physics, 11, 582-592 (1940)

3. R.S. Rivlin, Philosophical Transactions of the Royal Society of London A 240, 822, 459-490 (1948)

4. S. Zahorski, Archives of Mechanics, 5, 613-617 (1959)

5. S. Zahorski, Rozprawy inżynierskie, 10 (1), 193-207, in Polish (1962)

6. M. Major, I. Major, Advanced Materials Research, 1020, 165-170 (2014)

7. C.A. Coulson, A. Jeffrey, Mathematics models, in Polish (1982)

8. S. Kosiński, Elastic waves in rubber-like layered composites, in Polish (2007)

9. Z. Wesołowski, Acoustics of elastic body, in Polish (1989)

10. J. Melcer, Communication, 3, 5-10 (2007)

11. R. Cajka, M. Krejsa, Applied Mechanics and Materials, 501, 592-598 (2014) 